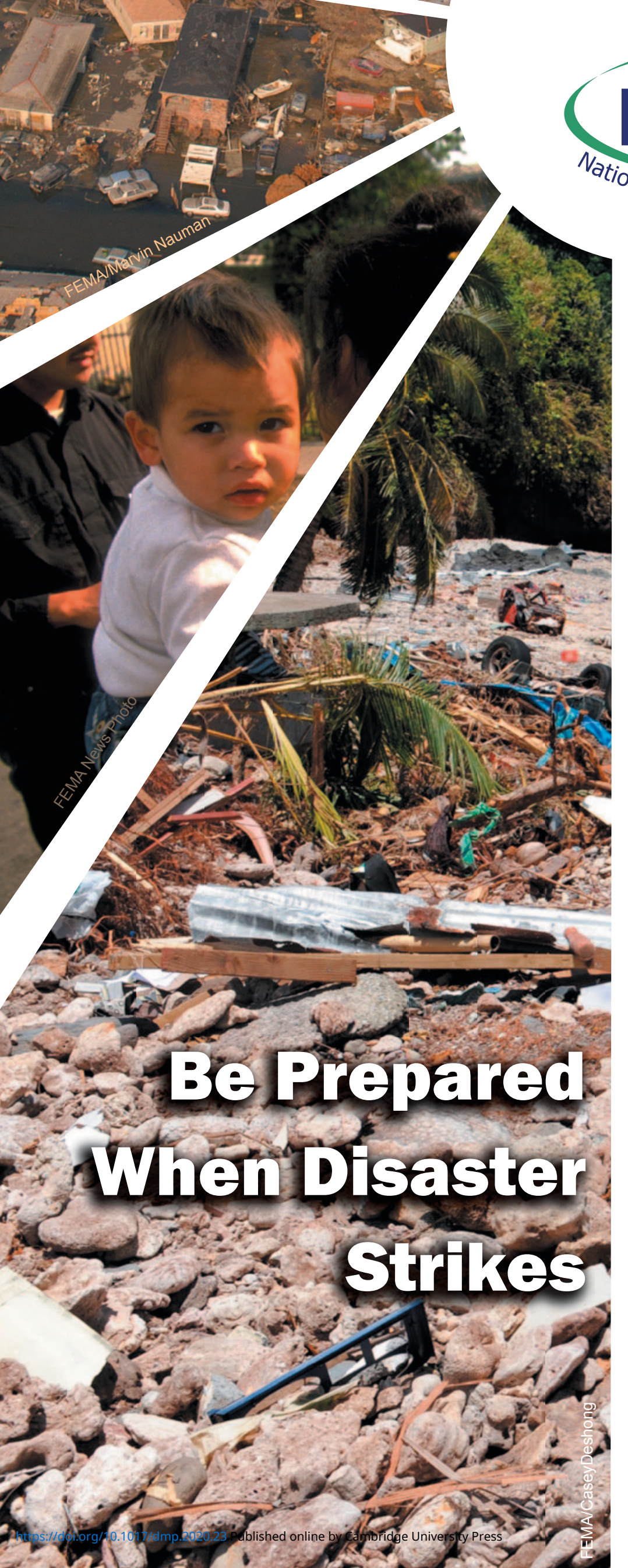

(8)

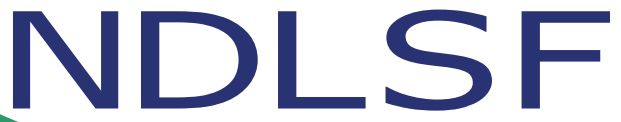

onal Disaster Life Support Foundation

\title{
National Disaster
}

Life Support ${ }^{\mathrm{TM}}$

Foundation

The NDLS courses are unique in that they are:

\section{- Competency-Based}

- Standardized

- Multi-Disciplínary

- All-Hazards

Over 100 training centers offer the courses globally.

More than 105,000 graduates.

2,500 Instructors.

Recognized for continuing education credit.

Recently revised for current content.

Endorsed by the National Disaster Life

Support Education Consortium.

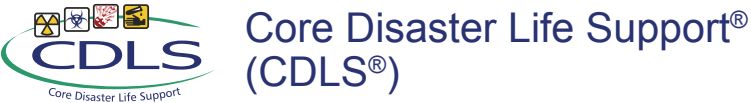

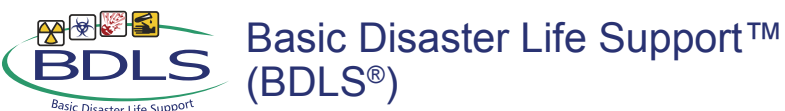

$$
\begin{aligned}
& \text { ADLS Advanced Disaster Life }
\end{aligned}
$$

For more information contact: info@ndlsf.org

To locate a course near you: http://register.ndlsf.org 


\section{CAMBRIDGE CORE}

For further information about this journal please go to the journal website at:

cambridge.org/dmp 